\title{
Enhancement of polymer dye lasers by multifunctional photonic crystal lattice
}

\author{
Christiansen, Mads Brøkner; Xiao, Sanshui; Mortensen, Asger; Kristensen, Anders
}

Published in:

Conference on Lasers and Electro-Optics, 2009 and 2009 Conference on Quantum electronics and Laser Science Conference. CLEO/QELS 2009

Publication date:

2009

Document Version

Publisher's PDF, also known as Version of record

Link back to DTU Orbit

Citation (APA):

Christiansen, M. B., Xiao, S., Mortensen, A., \& Kristensen, A. (2009). Enhancement of polymer dye lasers by multifunctional photonic crystal lattice. In Conference on Lasers and Electro-Optics, 2009 and 2009 Conference on Quantum electronics and Laser Science Conference. CLEO/QELS 2009 (pp. 1-2). IEEE.

\section{General rights}

Copyright and moral rights for the publications made accessible in the public portal are retained by the authors and/or other copyright owners and it is a condition of accessing publications that users recognise and abide by the legal requirements associated with these rights.

- Users may download and print one copy of any publication from the public portal for the purpose of private study or research.

- You may not further distribute the material or use it for any profit-making activity or commercial gain

- You may freely distribute the URL identifying the publication in the public portal 


\title{
Enhancement of Polymer Dye Lasers by Multifunctional Photonic Crystal Lattice
}

\author{
Mads Brøkner Christiansen ${ }^{1}$, Sanshui Xiao², Niels Asger Mortensen ${ }^{2}$, and Anders Kristensen ${ }^{1}$ \\ ${ }^{\prime}$ DTU Nanotech, Department of Micro- and Nanotechnology \\ ${ }^{2}$ DTU Fotonik, Department of Photonics Engineering \\ Technical University of Denmark \\ DK-2800 Kongens Lyngby, Denmark \\ mads.christiansen@nanotech.dtu.dk
}

\begin{abstract}
The light output of dye doped hybrid polymer band-edge lasers is increased more than 100 times by using a rectangular lattice photonic crystal, which provides both feedback and couples more pump light into the laser.

(C)2009 Optical Society of America

OCIS codes: (140.2050) Dye Lasers; (140.0140) Lasers and laser optics; (050.5298) Photonic crystals

Additional key words: nanoimprint, combined nanoimprint and UV lithography, Ormocer, band edge lasers
\end{abstract}

We present optically pumped hybrid polymer band edge lasers with a rectangular lattice providing laser feedback and also increasing the amount of pump light being absorbed [1]. The lasers are defined in a thin film of photodefinable Ormocore hybrid polymer[2], doped with the laser dye Pyrromethene 597. They are $375 \mathrm{~nm}$ thick slab waveguides with a rectangular lattice of $100 \mathrm{~nm}$ deep air holes imprinted into the surface, see Fig. 1. The short lattice constant $(a)$ is always $200 \mathrm{~nm}$, while the long lattice constant $(b)$ is varied from $351 \mathrm{~nm}$ to $360 \mathrm{~nm}$. A compact frequency doubled Nd:YAG laser $(532 \mathrm{~nm}, 5 \mathrm{~ns}$ pulses $)$ is used to pump the lasers from above the chip.

The lasers are fabricated in parallel on a $10 \mathrm{~cm}$ diameter wafer by combined nanoimprint and photolithography (CNP) [3]. CNP relies on a UV transparent quartz nanoimprint stamp with an integrated metal shadow mask. In the CNP process the photonic crystal is formed by mechanical deformation (imprinting) while the larger features are defined by UV exposure through the combined mask/mold.

Fig. 2 shows a typical band diagram for a laser. The two important points are circled. The point in the first band in the ГР direction provides feedback for lasing. The frequency of the laser can be tuned via the $a$ lattice constant. The frequency of the circled $\Gamma$ point depends on the $b$ lattice constant. Pump light is coupled into the laser when the inplane wave-vector matches the mode in band two or three. I.e. the optimum pump angle $(\theta)$ is

$$
\theta=\arcsin \left(\frac{k_{\|}}{k_{p}}\right)
$$

where $k_{p}$ is the wave-number of the $532 \mathrm{~nm}$ pump light and $k_{\|}$is the in-plane wave-number of the band at the frequency of the pump laser.

Fig. 3 is a photo of a laser pumped at the resonance angle. The pump light coming from above the chip is scattered into the chip plane. The orange laser emission is seen perpendicular to the scattered pump beam. A spectrum is inset. Fig. 4 shows measured and calculated data of how the optimum pump angle depends on the $b$ lattice constant. Two curves showing output vs pump intensity for the same laser on and off resonance are shown in Fig. 5. When the laser is pumped at the resonance angle the threshold drops to $470 \mathrm{~nJ} / \mathrm{mm}^{2}$, far below typical values for optically pumped dye lasers, and the output intensity increases more than two orders of magnitude.

Our results demonstrate that by careful design of the photonic crystal two optical functionalities can be combined at two different wavelengths in the same material. With their low thresholds and simple operation the lasers presented here provide an attractive way of integrating tuneable light sources into polymer lab-on-a-chip systems.

[1] Mads Brøkner Christiansen, Anders Kristensen, Sanshui Xiao, and Niels Asger Mortensen, "Photonic integration in k-space: Enhancing the performance of photonic crystal dye lasers", Appl. Phys. Lett. 93(23), in press (2008).

[2] Ormocore is commercially available from micro resist technology GmbH, Berlin, Germany, www.microresist.de.

[3] Mads Brøkner Christiansen, Mikkel Schøler, and Anders Kristensen, "Integration of active and passive polymer optics", Optics Express 15(7), 3931-3939 (2007). 


\section{CFQ4.pdf}

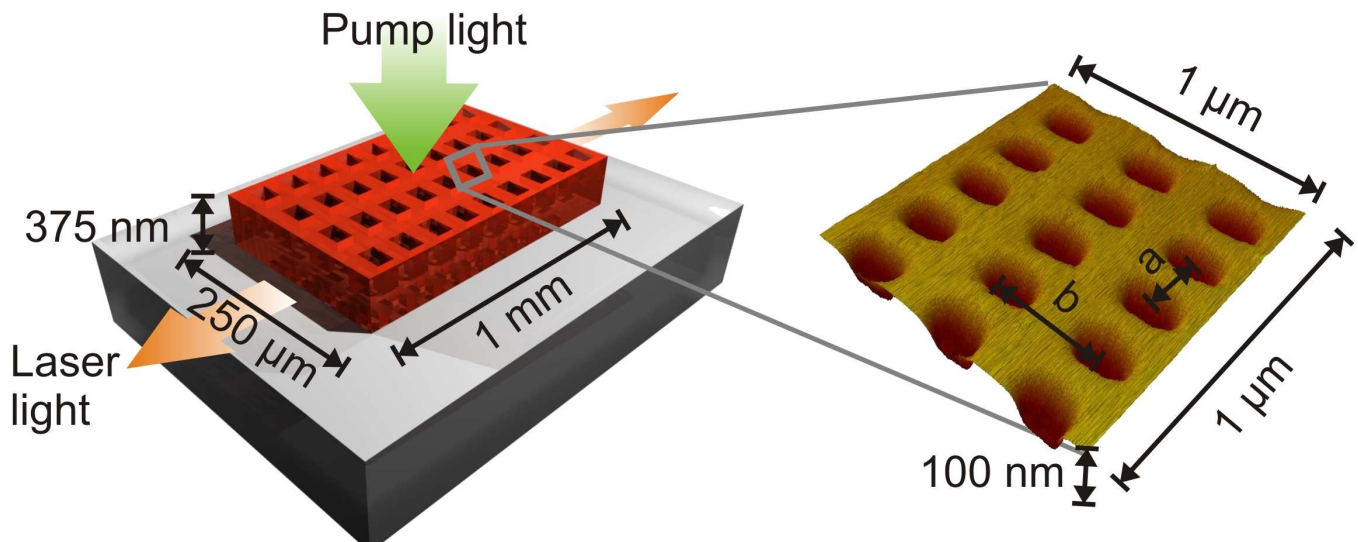

Fig. 1 Conceptual drawing of the resonance pumped lasers. The lasers are Pyrromethene 597 dye doped Ormocore slab waveguides on a glass substrate. The inset is an AFM image of the photonic crystal surface with the $a$ and $b$ lattice constants indicated.

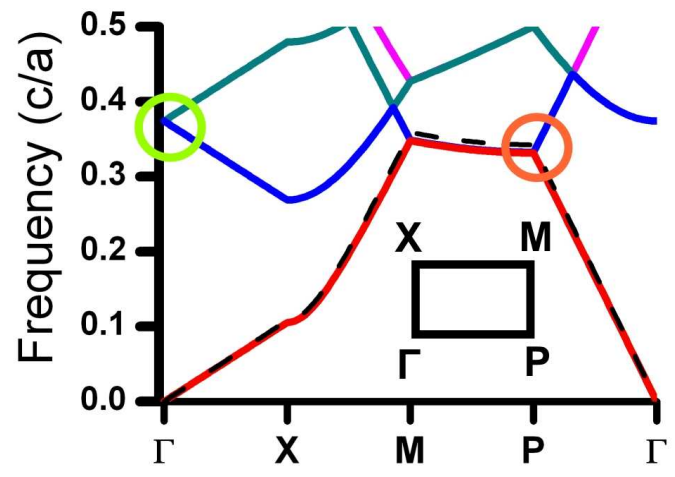

Fig. 2 Band diagram for a typical laser with the irreducible Brillouin zone inset. Modes above the dashed line are lossy. The band edge giving laser feedback is circled in orange. Its frequency depends on $a$. The point circled in green couples the pump light into the laser waveguide. Its frequency depends on $b$.

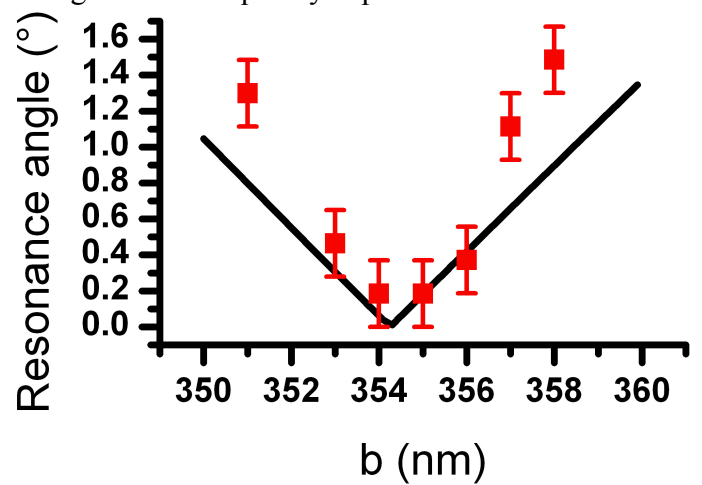

Fig. 4 Measured ( $\square$ ) and calculated (-) resonance pump angle as a function of $b$ lattice constant. Around $b=354$ $\mathrm{nm}$ the pump light hitting the chip at a $90^{\circ}$ angle is coupled into the laser.

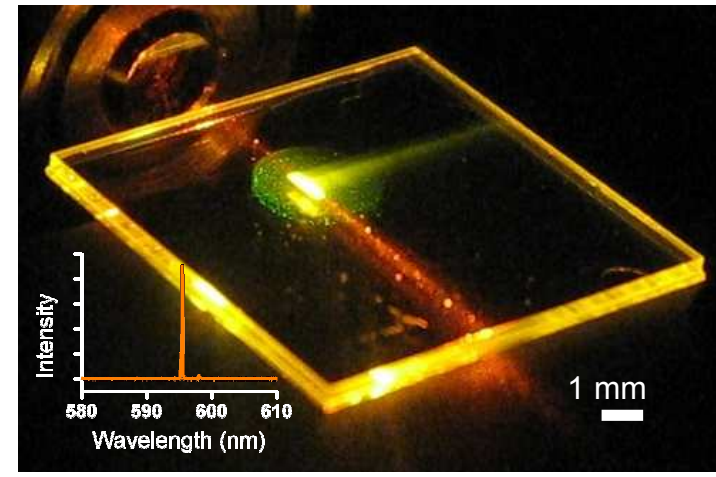

Fig. 3 Photo of a laser with the pump in the resonance angle. The laser is the bright rectangle in the green pump spot. The pump light is scattered into the chip plane, and the orange laser light is seen emitting from the ends of the laser. Inset shows a typical spectrum.

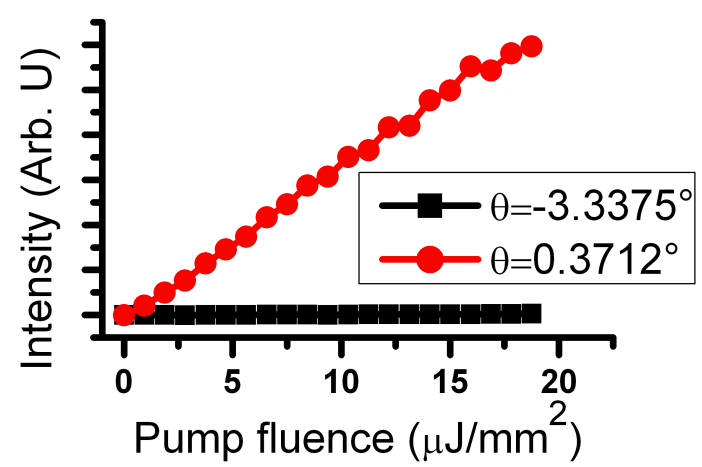

Fig. 5 Output versus pump intensity for the same laser $(b=355 \mathrm{~nm})$ pumped on $(\bullet)$ and off $(\boldsymbol{\bullet})$ resonance. The off-resonance signal is barely seen, but it has a laser threshold of $7.9 \mu \mathrm{J} / \mathrm{mm}^{2}$. 